\title{
A Hybrid Classroom Instruction in Second Language Teacher Education (SLTE): A Critical Reflection of Teacher Educators
}

\author{
https://doi.org/10.3991/ijet.v12i05.6989 \\ Nani Solihati \\ University of Muhammadiyah, Prof. Dr Hamka, Jakarta, Indonesia \\ Nani solihati@uhamka.ac.id \\ Herri Mulyono \\ University of Muhammadiyah, Prof. Dr Hamka, Jakarta, Indonesia \\ hmulyono@uhamka.ac.id
}

\begin{abstract}
Hybrid instruction, which combines face-to-face classroom interaction and virtual activities, has been a growing interest for many teachers in universities, particularly those in teacher education programmes. This article presents my colleague's as well as my own critical reflections on our experience with practising hybrid classroom instruction in SLTE in a private university in Indonesia. Within this hybrid classroom, Google Classroom (GC) was incorporated as a companion of the face-to-face (F2F) classroom learning sessions of twenty-two preservice teachers taking the curriculum and materials development (CMD) module. To help with our reflection, we took notes during our observation and asked the students to write a journal after each of our teaching sessions. We highlight several benefits and challenges when incorporating GC in a hybrid classroom. Implications for the practice of a hybrid classroom in SLTE, particularly within the Indonesian higher education context, are also offered.
\end{abstract}

Keywords - hybrid classroom, virtual activities, preservice teacher, teacher education.

\section{$1 \quad$ Introduction}

Hybrid instruction, also known as blended learning or mixed-mode learning, is an instructional approach that combines face-to-face (F2F) classroom instruction and online learning activities [1]-[3]. In practice, such a definition has resulted in numerous debates among researchers and practitioners. The three main topics of debate found in the literature are centered on how the portion of the F2F and online instructions is determined, on how teachers and administration select technological tools for hybrid classroom and teachers' application of instructional strategies [1]. In regard to the instructional portion in a hybrid environment, for example, many authors have different views. For example, Brown 2001, cited in [4] suggests a portion of 
$90 \%$ online and $10 \%$ F2F or $10 \%$ or $90 \%$ online. Moreover, Harrington [5] advises a $20 \%-80 \%$ replacement of F2F classroom sessions while Black [6] aims to balance the portions between the online and F2F classroom interaction at the level of 50\%.

In the context of higher education, hybrid modes of instruction have been widely practiced, e.g. see [2], [4] and [7]. A number of studies have reported on the benefits of hybrid instruction practices, such as their promotion of the flexibility of instruction [4], [8], their aiding of faculty members in terms of managing the classroom learning of large classes [7], [9], their promotion of students' personalised and learning independence Graham, 2006 as cited in [3], their improvement of students' attendance to the learning activities [10], their enhancement of students' learning achievements [11] and their facilitation of sustainable teaching and learning practices [3].

The review of literature also shows that hybrid instruction is extensively practised in the context of a teacher education (TED) programme. For instance, Alayyar et al. [8], Altun, Gulbahar and Madran [12], Heba and Nouby [13], Yeh, Huang and Yeh [14] and Yilmaz and Orhan [15] have reported on the practice of hybrid instruction in TED. According to Heba and Nouby [13], the incorporation of hybrid learning approach in TED is primarily aimed to offer a direct experience to the prospect teachers regarding how to use technology in classroom learning before their real teaching with the technology.

To gain benefits from the hybrid mode of instruction and to provide our students with first-hand experience with technology use in classroom teaching, we developed a hybrid format of our teaching module "Curriculum and Materials Development (CMD)" at a second language teacher education (SLTE) in a private university in Indonesia. This present article discusses our teaching practices within a hybrid environment and our self-reflection of it. In this article, self-reflection is perceived as a professional development tool that helps us understand the pedagogical nature of our past practices, examine its quality and, accordingly, to search for alternative improvements for future practice. Our self-reflection is critical to yield the voice of teacher educators as the main actors in the hybrid instruction practice, which is a topic that has been underexplored in the literature. Thus, this article will contribute to the current body of literature on the area of hybrid instruction in the context of higher education, particularly second language teacher education (SLTE).

\section{Description of the Hybrid Classroom Instruction}

\subsection{Classroom context}

The hybrid classroom activity was carried out in a faculty of teacher training and pedagogy in a private university in Indonesia where the authors were members of the teaching staff. The activity was performed in curriculum and material development (CMD) classroom sessions and lasted for six months. The classroom that we used for face-to-face interaction was room A.305, located on the third floor of the faculty building. Apart from teachers' and students' desks, the classroom included a whiteboard, one projector and a university network for internet access. No classroom per- 
sonal computers (PCs) were available. Therefore, in our hybrid classroom, students were required to bring their own laptops in order able to participate in the hybrid classroom.

\subsection{Technology infrastructure at the site}

In early 2014, our university made several significant changes in its technology infrastructure policy. One of the changes was its choice to use Gmail as its internal email server. The university migrated the local email server into the Google email platform. Such a choice was made because the Gmail platform was viewed as offering benefits to our university, particularly for the teaching staff and students. The migration to the Gmail platform allowed the University, as an educational domain, to access Google's GAFE (Google applications for education) — in particular, Google Classroom and Google Drive. Google Classroom enabled the teaching staff to create a virtual classroom for hybrid learning while Google Drive offered virtual spaces for instructors to keep their teaching and learning materials online. To enable all members of the teaching staff and students to have access to these two applications, the University, through the centre of information and communication technology, provided university email accounts for teaching staff and students. Each member of the teaching staff and each student were also given approximately a 5TB (terabyte) virtual storage capacity in the University's Google Drive to support online learning activities.

\subsection{Setting up the Google Classroom application for hybrid classroom practice}

Prior to setting up Google Classroom (henceforth GC), we read several literatures on Google apps and their procedure for classroom us, such as Brumbaugh, Calhoon, Musallam, and Pronovos (2014), Keeler and Miller [17] and Smith (2015). As suggested by Smith [18], we also obtained valuable insights from the Google Classroom Support Centre as well as from member posts in the Google for Education Help Forum. In addition to these references, we observed a number of applications of GC in many Indonesian schools and universities to link between theory and practices. Based on these references and early observations, we developed GC to facilitate our hybrid learning activities.

A GC was set up in the "Curriculum and materials development (CMD)" course, and the learning environment in GC occurred in an asynchronous mode. Within this mode of learning, students' activities in GC were not time bound, which thus allowed them to work on their online learning activities at their own pace [19]. The design of GC included three main menus in the teacher page: 'stream', 'students' and 'about'. It also featured two main menus in the student page: 'stream' and 'students'. In the 'students' page, the assignment menu appeared as a sidebar menu. In the 'stream' menu, students could obtain updates about teaching and learning materials as well as classroom activities. The 'about' menu informed the students about the course, syllabus, textbook, presentation schedule and presentation topic. 
In the GC design, GC was linked to three other Google apps, including Google Drive, Google Docs and Google Calendar. Google Drive enabled teachers and students kept the teaching and learning materials in the virtual classroom database. This virtual classroom database enabled the students to have access to the learning resources without the restrictions of place and time. Google Docs facilitated teachers' and students' collaboration while Google Calendar keeps students updated with their learning activity

\subsection{Instructional delivery methods}

The hybrid classroom provides opportunities for teachers to carry out and combine two modes of instructional delivery: face-to-face and virtual modes. As designed for our classroom instruction, the face-to-face (henceforth F2F) classroom sessions were aimed 1) to enable teachers to deliver the teaching and learning materials, 2) to facilitate students' group presentations and 3) for classroom discussions. The F2F was done once in a week with 100 minutes duration for each session. In total, there were eleven topics to cover during twelve F2F sessions. The entire F2F instructional classroom procedure followed the below lesson plan:

Objective: 1) to help preservice teachers understand the concepts, fundamentals and procedures of curriculum development, 2) to enable preservice teachers to evaluate the current curriculum and 3) to help them develop curriculum and learning materials.

Textbook: "Language Curriculum Design" by I.S.P Nation and John Macalister (2010)

Time: Eleven sessions, 100 minutes each

Procedure:

1. Pre-presentation stage (10 minutes). In this stage, students, in groups, prepared for their presentations. This included preparing for the presentation paper, laptops, presentation files and preparing the projector.

2. Presentation stage ( 25 minutes). In this stage, students presented their paper related to the topic already given. The presentation was in group.

3. Discussion stage (40 minutes). In the discussion stage, students participated in question-and- answer sessions related to the presentation.

4. Teacher's feedback (15 minutes). The teacher provided feedback related to students' presentation and discussion.

5. Teacher's assignment (10 minutes). The teacher informed the students about tasks they needed to complete.

In addition to F2F, virtual activities were carried out to facilitate students' learning. According to Harrington [5], the percentage of virtual activities within the F2F-C classroom sessions ranges between $20 \%$ and $80 \%$. In our context, the aim of employing a virtual classroom was not to substitute the F2F sessions or to determine the percentage of virtual activities; rather, it was to provide students with an online application that supported classroom learning [4]. Specifically, the virtual classroom was employed 1) to inform students' about upcoming activities, 2) to help students re- 
trieve teaching and learning materials online from Google Drive, 3) to distribute classroom assignments, 4) to facilitate collaborative learning among students and 5) to bridge communications between teachers and students and among students.

The virtual activities were scheduled between Monday and Friday, and there was no time restriction for these activities except for the assignment. For the assignment, we gave the students a certain amount of time to complete the classroom assignment. For example, we created due dates for students in terms of when to upload their assignment, revisions and resubmit their work.

\section{Methodology}

\subsection{Reflective teaching}

Reflective teaching is viewed as a method for teachers to 'think about what [has] happened, why it happened, and what else could have been done to reach their goals' Cruickhank and Applegate, 1981, p. 553 cited in [20]. Through reflection on their teaching practice, teachers can learn about their own classroom instruction, students and their interactions during the classroom instruction. This self-learning method enables teachers to connect between what they have learned in the literature and its actual practices (Smith, 2012). Therefore, when reflecting on their teaching, teachers in addition to considering their own perspective, students' perspectives and, in a broader sense, the parents' perspectives, they also need to consider the classroom context [20].

In conducting a reflection on our experience of practising teaching and learning in a hybrid environment, we employed the reflection-on-action (RoA) framework. Within this framework, the reflection occurred after classroom teaching and was focused on the 'cognitive process of teaching' [20, p. 9]. We followed Burhan-Horasanlı and Ortaçtepe's [22] procedure. First, we reflected on our experience when conducting teaching and learning activities in the hybrid environment. Second, we reviewed our documents and teaching notes. Then, we evaluated the classroom procedures, the role of technology and the face-to-face sessions and our students' classroom learning and interaction.

\subsection{The participants}

As this article focuses on the reflection of teaching practices, ta colleague and I took on the role as participants at the faculty of teacher training and pedagogy. During the implementation of the hybrid classroom format, I took the role as a teacher, while my colleague was my collaborator as well as a classroom observer. In addition, twenty-one preservice teachers registered in our CMD module were involved in our hybrid classroom practice. The preservice teachers included nine males and twelve females. Our observations prior to the present study showed that the twenty-one preservice teachers were able to operate basic computer applications, which included their ability in word processing, and their ability to create an electronic presentations and multi- 
media applications. Our students were able to operate an internet searching engine, conduct email correspondence, upload and download applications and files from websites as well as perform offline and online printing. In addition to these computer skills, we observed that our students were able to make a connection between their smartphones and computers (also laptops), particularly in terms of connecting the Gmail application, Google Drive, Google Docs and Google classroom application.

\subsection{Data collection methods and the analysis}

We employed two methods of data collection to help us reflect on our hybrid classroom teaching experience, namely self-observation and a student journal. According to Richards [23, p. 118], self-observation enables teachers to observe, evaluate and manage their own behaviour in order to gain a better understanding of their instructional activities. In conducting this self-observation, teachers made an observation note and used information gathered from lessons plans, computer logs and feedback on students' work. In addition to self-observation, student journals were also used to facilitate our reflection. We asked our students to write about their learning experiences in the hybrid environment after each F2F session. The data collected from these two instruments were then transcribed and analysed using a content analysis. We adopted Rayford's [24] method for conducting a content analysis in that, first, we coloured the codes from the emerging themes from our observations as well as students' journals. Then, on a sheet of paper, we gathered all of the codes from the emerging themes to determine their frequency and to detect patterns. Finally, we employed such frequency and pattern from the codes to guide our reflection and to outline the discussion session.

\section{$4 \quad$ Findings and discussion}

The followings themes emerged from our reflection:

\subsection{Using GC in a hybrid classroom helped teachers inform the students about classroom learning activities and helped with the delivery of instructional materials, but it did not promote the quality of F2F classroom sessions.}

In our practice, GC was purposefully employed to help us inform the students' about the topic they were going to learn. Throughout the GC stream, we also informed the students about a list of books and journals they were required to read. We noticed from our observation that most of our students were well informed about the topic they were going to learn about, and many had downloaded and read the learning materials. When we asked the students if they were already familiar with the topic that they were going to learn, most of them answered positively. This indicated that the information we distributed to the students via GC was well received by the students. 
Besides helping the teachers to inform the students about classroom learning activities, GC facilitated us in the delivery of instructional materials prior the classroom sessions. As suggested by [18], GC was connected to our University Gmail account. Such a connection allowed us to upload the instructional materials into the Google Drive application which were accessible to the students. It was interesting that students reported to have accessed these instructional materials through their smartphones rather than their laptops. From our record, most of the students (19 of 21 students) used a smartphone to login into GC and download the materials. Many of these students also stored the learning materials on their phone memory so that they could easily access it offline. Similar benefits of using a smartphone to provide students with access to the teaching and learning materials prior to F2F classroom sessions is also discussed in the literature, e.g. Baran [25], Husbye and Elsener [26] and Vázquez-Cano [27].

Despite the fact that students' virtual activities in GC had allowed them to access the learning materials days before, it is quite surprising that many came to the F2F classroom session without relevant knowledge related to the learning topic. In other words, students' direct access to teaching and learning materials prior to an F2F classroom session does not imply students' proper understanding of the learning topic. During students' presentation session, for example, we observed that students were not able to appropriately explain contents from the textbook. Additionally, some did not respond to our questions during this stage, or they remained quiet. When we asked the students why they had little knowledge about the topic they were learning, most of the students responded that they did not read before class or, for some who read, they had attained only a limited understanding of the textbook contents.

The result of our classroom observation showed that students' lack of reading prior to class and their lack of understanding of the learning materials negatively affected the quality of F2F classroom sessions. As students had a little knowledge about the topic they were going to learn, we spent a substantial amount of time on the reading and on checking students' understanding of the contents from the reading accordingly. In addition, students' active discussion of the materials (i.e. students' active learning) that we had expected to widen the contexts of the learning materials could not occur. Accordingly, we felt that the quality of F2F interactions in the hybrid classroom did not seem to be much different from the quality of $\mathrm{F} 2 \mathrm{~F}$ interaction that we had within a traditional classroom. In other words, the use of GC in a hybrid learning environment did not enhance the quality of F2F classroom learning as suggested by earlier research, e.g. [1] [7].

We identified several reasons that led to a lack of students' reading before the classroom session. First, students had downloaded the learning materials, but they admitted that they had not read them. Once in our classroom observation, we surveyed the student participants and asked if they read before the classroom session. We found that of the twenty-one students, only eight students or $38 \%$ had read the materials before they came to the F2F classroom sessions. A lack of students' compliance with reading assignment prior the classroom as reported in this present article corresponds with many of the earlier studies, such as Clump, Bauer, and Bradley [28], Hoeft [29] and Aagaard, Conner, and Skidmore [30]. 
In addition to their incompletion of the reading assignments, students who read the materials before class did not have proper ability to comprehend the learning materials, which were written in English. Analysis of students' journal showed that of the eight students who had read the learning materials before the classroom session, seven felt it was difficult to understand English reading texts. From the literature, we understand that students' reading difficulty has been a critical issue in the higher education setting [31], for example, [32]-[34], particularly in the context where English is taught as a foreign language (FL). From students' journals, we identified some contributing factors to the issue that correspond to earlier studies, such as vocabulary issues [35], [36], inappropriate prior knowledge [37], students' low language proficiency and reading motivation [35]-[37].

While students' lack of reading, andlack of understanding and their impact on the F2F classroom were already apparent despite the availability of learning resources, we came to understand that these issues emerged as a sequence of students' ignorance of the role of assigned reading. This, in turn creates students' uncertainty in terms of what to do with the reading assignment. During the course, for example, we noted some students kept asking us about the pages from the book they were required to read or what they should read. Maher and Mitchell [38] argued that students possess a strong motivation to read the learning materials assigned to them, but they remained unsure about the workloads and the necessary skills required to do so. In particular, students were less exposed to information about (1) workload of the reading assignment, (2) the procedures required by the students, (3) the necessary skills needed for the assignment [38, p. 142]. These issues need to be addressed to improve our hybrid classroom practice. A review of the literature suggests two possible alternatives that can address the issues: evaluate the pedagogical role of the reading assignment see [39] and provide reading scaffolding to the students during the reading activities see for example [34], [40].

\subsection{Preservice teachers' reluctance to communicate in GC}

GC was primarily used to bridge communications between teachers and students and among the students themselves. The result of our observation shows that students were reluctant to use GC as an online communication tool. During students' online activity in GC, very few students (five of twenty-one students) responded to our online feedback or communicated their learning progress to us via GC message or the comment features. Despite the fact that the GC interface was quite similar to features in social media applications, such as the comment feature on Facebook or the mention feature in Twitter, such a similarity did not seem to attract most of our student participants to communicate their learning activity online in GC. Instead, the students were observed to frequently use social media applications to communicate with their peers and us. This condition corresponds to earlier studies that noted students' use of social media for interaction and communication in learning, e.g. [41][42][43]. The reasons students preferred to use social media applications instead of the GC communication tools were unclear. However, it is important to note that, within the Indonesian class- 
room context, teacher-student communication through smartphone applications such as WhatsApp, Facebook and Twitter is something in common.

\subsection{GC facilitated the learning assignment and feedback}

Besides helping with the distribution of learning materials, the use of GC benefited our creation and organisation of students' assignments and feedback. We felt that creating an assignment and distributing it to the students in GC were easy tasks. As suggested by G. Smith [18], we created an assignment template on Google Drive, stored it in the GC database and distributed it to the students. More importantly, GC feature allowed us to attach multimedia files in an assignment and to schedule the assignment for distribution to the students. Interestingly, students would receive an email notification as soon the assignment was created in the GC.

In addition to the teachers' ease in creating, managing and distributing assignments to the students, GC allowed us to grade the students' essays and provide immediate feedback. The GC features for grading and giving feedback were, in fact, userfriendly. It was interesting for us to learn that the GC grading and feedback features were similar to features in social media applications like Facebook and Twitter. More importantly, GC provided a comments space to allow for teacher-student interactions.

Despite the two benefits discussed above, we identified several issues regarding the students' assignments and the feedback in GC. First, we noticed that the assignment types were limited. Compared to other online learning platforms, e.g. see [44], we found only one type of assignment available in GC: an essay, see also in [18]. Although multiple choice was possible through Google Form, this alternative was not familiar to us and thus was difficult to carry out in our practice. Second, although GC has a student report menu that enables teachers to observe students' online learning progress, such a menu was restricted to university ICT staff only. Thus, we were unable to access the menu, and, accordingly, students' online learning progress was monitored manually using an Excel spreadsheet.

\section{Conclusion and implications}

Our practice of hybrid classroom instruction suggests that virtual activities should not be viewed as a division of learning environment or as a replacement for F2F sessions to any degree. Instead, these activities should be used as learning support and as resources for both teachers and students outside the classroom. With this respect, virtual classroom activities should be viewed from two perspectives. First, for teachers, a virtual classroom is a pedagogical tool that helps teachers achieve their instructional objectives. Second, the virtual classroom should be presented as an extension of students' learning in that students were given opportunities to continuously access their learning activities after their F2F sessions.

The practice of hybrid classroom benefits teachers and students in two ways: First, it eases the delivery of teaching and learning materials prior to classroom activity. Google apps enable the students to retrieve the learning materials so that they have 
enough time to read and understand the materials before attending the real classroom sessions. Second, it benefits the teachers by creating and distributing learning assignment to the students. Using GC to facilitate a hybrid learning classroom allows teachers to provide feedback directly to the students. To capitalise on such benefits of a hybrid classroom, it is important that SLTE administrators provide technological training for both teachers and students on the use of GC application as well as other technology available in the University. Similar attempts have been made in other universities when using technology for academic purposes [27].

Despite the benefits, using GC to facilitate hybrid learning does not enhance the quality of F2F classroom interactions. The main issue found was students' lack of reading compliance prior to $\mathrm{F} 2 \mathrm{~F}$ sessions. To address this issue, teachers at SLTE should be required to evaluate their pedagogical role in relation to the reading assignment. They should also be required to facilitate the students with strategies for reading English textbooks.

\section{References}

[1] E. Oh and S. Park, 'How are universities involved in blended instruction?', Educ. Technol. Soc., vol. 12, no. 3, pp. 327-342, 2009.

[2] W. He, D. Gajski, G. Farkas, and M. Warschauer, 'Implementing flexible hybrid instruction in an electrical engineering course: The best of three worlds?', Comput. Educ., vol. 81, pp. 59-68, 2015. https://doi.org/10.1016/j.compedu.2014.09.005

[3] W. I. O'Byrne and K. E. Pytash, 'Hybrid and Blended Learning', J. Adolesc. Adult Lit., vol. 59, no. 2, pp. 137-140, 2015. https://doi.org/10.1002/jaal.463

[4] R. Woods, J. D. Baker, and D. Hopper, 'Hybrid structures: Faculty use and perception of web-based courseware as a supplement to face-to-face instruction', Internet High. Educ., vol. 7, no. 4, pp. 281-297, 2004. https://doi.org/10.1016/j.iheduc.2004.09.002

[5] A. M. Harrington, 'Problematizing the hybrid classroom for ESL/EFL students', Electron. J. English as a Second Lang., vol. 14, no. 3, pp. 1-13, 2010.

[6] G. Black, 'A comparison of traditional, online, and hybrid methods of course delivery', $J$. Bus. Adm. Online, vol. 1, no. 1, pp. 1-9, 2002.

[7] S. Riffell and D. Sibley, 'Using web-based instruction to improve large undergraduate biology courses: An evaluation of a hybrid course format', Comput. Educ., vol. 44, no. 3, pp. 217-235, 2005. https://doi.org/10.1016/j.compedu.2004.01.005

[8] G. M. Alayyar, P. Fisser, and J. Voogt, 'Developing technological pedagogical content knowledge in pre-service science teachers: Support from blended learning', Australas. $J$. Educ. Technol., vol. 28, no. 8, 2012. https://doi.org/10.14742/ajet.773

[9] H. Wang, 'The Analysis of Teacher Talk in " Learner-centered " Teaching Mode', vol. 8, no. 4, pp. 1172-1174, 2014.

[10] J. Chen and T.-F. Lin, 'Class attendance and exam performance: A randomized experiment', J. Econ. Educ., vol. 39, no. 3, pp. 213-227, 2008. https://doi.org/10.3200/ JECE.39.3.213-227

[11] M. Kendall, 'Teaching online to campus-based students: The experience of using WebCT for the community information module at Manchester Metropolitan University', Educ. Inf., vol. 19, no. 4, pp. 325-346, 2001. https://doi.org/10.3233/EFI-2001-19404 
[12] A. Altun, Y. Gulbahar, and O. Madran, 'Use of a content management system for blended learning: Perceptions of pre-service teachers', Turkish Online J. Distance Educ., vol. 9, no. 4, 2008.

[13] E.-D. Heba and A. Nouby, 'Effectiveness of a blended e-learning cooperative approach in an Egyptian teacher education programme', Comput. Educ., vol. 51, no. 3, pp. 988-1006, 2008. https://doi.org/10.1016/j.compedu.2007.10.001

[14] Y. Yeh, L. Huang, and Y. Yeh, 'Knowledge management in blended learning: Effects on professional development in creativity instruction', Comput. Educ., vol. 56, no. 1, pp. 146156, 2011. https://doi.org/10.1016/j.compedu.2010.08.011

[15] M. B. Yilmaz and F. Orhan, 'Pre-service English teachers in blended learning environment in respect to their learning approaches', TOJET Turkish Online J. Educ. Technol., vol. 9, no. $1,2010$.

[16] K. Brumbaugh, E. Calhoon, R. Musallam, and R. Pronovost, Creating a Google Apps Classroom: The educator's cookbook. Shell Education, 2014.

[17] A. Keeler and L. Miller, 50 things you can do with Google Classroom. Dave Burgess Consulting, Incorporated, 2015.

[18] G. Smith, 'Letting Google do the heavy lifting - An introduction to, and review of Google classroom', ICU Lang. Res. Bull., vol. 30, pp. 1-8, 2015.

[19] A. Perveen, 'Synchronous and asynchronous e-language learning: A case study of virtual university of Pakistan', Open Prax., vol. 8, no. 1, pp. 21-39, 2016. https://doi.org/10.5944/openpraxis.8.1.212

[20] T. S. C. Farrell, Reflective language teaching: From research to practice. London, New York: Continuum, 2007.

[21] D. Smith, 'Supporting new teacher development using narrative-based professional learning professional learning', Reflective Pract., vol. 13, no. 1, pp. 149-165, 2012. https://doi.org/10.1080/14623943.2011.626020

[22] E. Burhan-Horasanlı and D. Ortaçtepe, 'Reflective practice-oriented online discussions: A study on EFL teachers' reflection-on, in and for-action', Teach. Teach. Educ., vol. 59, pp. 372-382, Oct. 2016. https://doi.org/10.1016/j.tate.2016.07.002

[23] J. C. Richards, 'Beyond training: Approaches to teacher education in language teaching', Lang. Teach., vol. 14, pp. 3-8, 1990.

[24] C. R. Rayford, 'Reflective practice: The teacher in the mirror', Doctoral Thesis. University of Nevada, 2010.

[25] E. Baran, 'A review of research on mobile learning in teacher education.', Educ. Technol. Soc., vol. 17, no. 4, pp. 17-32, 2014.

[26] N. E. Husbye and A. A. Elsener, 'To move forward, we must be mobile: Practical uses of mobile technology in literacy education courses', J. Digit. Learn. Teach. Educ., vol. 30, no. 2, pp. 46-51, 2013. https://doi.org/10.1080/21532974.2013.10784726

[27] E. Vázquez-Cano, 'Mobile distance learning with smartphones and apps in higher education.', Educ. Sci. Theory Pract., vol. 14, no. 4, pp. 1505-1520, 2014.

[28] M. A. Clump, H. Bauer, and C. Breadley, 'The extent to which psychology students read textbooks: A multiple class analysis of reading across the psychology curriculum', J. Instr. Psychol., vol. 31, no. 3, p. 227, 2004.

[29] M. E. Hoeft, 'Why university students don't read: What professors can do to increase compliance', Int. J. Scholarsh. Teach. Learn., vol. 6, no. 2, p. Article 12, 2012.

[30] L. Aagaard, T. W. Conner, and R. L. Skidmore, 'College textbook reading assignments and class time activity', J. Scholarsh. Teach. Learn., vol. 14, no. 3, pp. 132-145, 2014. https://doi.org/10.14434/josotl.v14i3.5031 
[31] H. Masduqi, 'Efl Reading In Indonesian Universities: Perspectives And Challenges in Cultural Contexts', J. Teach. Educ., vol. 3, no. 3, pp. 385-397, 2014.

[32] S. M. Abdelhalim, 'Developing EFL Students' Reading Comprehension and Reading Engagement: Effects of a Proposed Instructional Strategy', Theory Pract. Lang. Stud., vol. 7, no. 1, pp. 37-48, 2017. https://doi.org/10.17507/tpls.0701.05

[33] N. Johnston, H. Partridge, and H. Hughes, 'Understanding the information literacy experiences of EFL (English as a foreign language) students', Ref. Serv. Rev., vol. 42, no. 4, pp. 552-568, 2014. https://doi.org/10.1108/RSR-05-2014-0015

[34] K. Starcher and D. Proffitt, 'Encouraging students to read: What professors are (and aren't) doing about it', Int. J. Teach. Learn. High. Educ., vol. 23, no. 3, pp. 396-407, 2011.

[35] E. Irfanti, 'A survey of the English reading habits of EFL students in Indonesia', TEFLIN J., vol. 23, no. 2, pp. 149-164, 2012.

[36] B. Y. Cahyono and Widi, 'The teaching of EFL reading in the Indonesian context: The state of the art', TEFLIN J., vol. 17, no. 1, pp. 36-58, 2006.

[37] S. Kweldju, 'English department students interest and strategies in reading their content area text books', TEFLIN J., vol. 8, no. 1, pp. 140-117, 1996.

[38] J. Maher and J. Mitchell, 'I'm not sure what to do! Learning experiences in the humanities and social sciences', Issues Educ. Res., vol. 20, no. 2, pp. 137-148, 2010.

[39] B. D. Brost and K. A. Bradley, 'Student compliance with assigned Reading: A case study', J. Scholarsh. Teach. Learn., vol. 6, no. 2, pp. 101-111, 2006.

[40] A. Van Staden, 'Put reading first: Positive effects of direct instruction and scaffolding for ESL learners struggling with reading', Perspect. Educ., vol. 29, no. 4, pp. 10-21, 2011.

[41] N. Dabbagh and A. Kitsantas, 'Personal Learning Environments, social media, and selfregulated learning: A natural formula for connecting formal and informal learning', Internet High. Educ., vol. 15, no. 1, pp. 3-8, 2012. https://doi.org/10.1016/ j.iheduc.2011.06.002

[42] J. Gikas and M. M. Grant, 'Mobile computing devices in higher education: Student perspectives on learning with cellphones, smartphones \& social media', Internet High. Educ., vol. 19, pp. 18-26, 2013. https://doi.org/10.1016/j.iheduc.2013.06.002

[43] C. M. K. Cheung, P.-Y. Chiu, and M. K. O. Lee, 'Online social networks: Why do students use facebook?', Comput. Human Behav., vol. 27, no. 4, pp. 1337-1343, 2011. https://doi.org/10.1016/j.chb.2010.07.028

[44] H. Mulyono, 'Using Quipper as an online platform for teaching and learning English as a foreign language', Teach. English with Technol., vol. 16, no. 1, pp. 59-70, 2016.

\section{$7 \quad$ Authors}

Nani Solihati is an associate professor at Faculty of Teacher Training and Pedagogy, University of Muhammadiyah, Prof. Dr Hamka (UHAMKA). Her research interests include neurolinguistics, discourse analysis, language and literature.

Herri Mulyono is a lecturer at Faculty of Teacher Training and Pedagogy, University of Muhammadiyah Prof. Dr Hamka (UHAMKA). He is a PhD candidate at University of York, UK. His research interests include the teaching and learning strategies for English as a foreign language and computer assisted language learning (CALL).

Article submitted 09 April 2017. Published as resubmitted by the authors 18 May 2017. 